Organisational justice

\section{Psychosocial work environment and health: new evidence}

\section{Johannes Siegrist}

\section{"New" occupational health research for science and policy}

D espite profound changes in modern working life occupational health research has maintained a rather narrow view of its topic, dealing almost exclusively with physical, chemical, or otherwise material conditions. ${ }^{12}$ In view of a substantial body of scientific evidence of adverse effects on health produced by a stressful psychosocial work environment this restriction is no longer justified. ${ }^{3}{ }^{4}$ The term "psychosocial work environment" has been introduced to delineate the range of sociostructural work related opportunities that is available to an individual person to meet his or her needs of wellbeing, productivity, and positive self experience. ${ }^{5}$ Two aspects of positive self experience are of particular importance for wellbeing and health at work: self efficacy and self esteem.

The demand-control model of work related stress posits that job tasks characterised by high psychological demands in combination with a low level of decision latitude or task control evoke recurrent stress reactions by suppressing positive experiences of self efficacy. ${ }^{6}$ A complementary model of an adverse psychosocial work environment, effort-reward imbalance, is based on the notion of reciprocity of work contracts where effort at work is reciprocated by socially defined rewards that include money, esteem, and status in terms of promotion prospects and job security. ${ }^{7}$ Failed contractual reciprocity (an imbalance between high efforts and low rewards at work) adversely affects self esteem and elicits longlasting stress reactions. Both models were shown to predict a range of stress related diseases in employed people. ${ }^{3-8}$

New results from the Whitehall II study of British civil servants published in this issue suggest that health adverse effects of low self esteem at work are not restricted to contractual unfairness but may extend to less specific experiences of relational injustice at work. ${ }^{9}$ The main findings of this study show that employees who suffer from inappropriate behaviour of their superiors (relational injustice) are at increased risk of poor self rated health at two subsequent time intervals (after three and six years on average). Moreover, declining organisational justice over time increases the risk of poor health whereas an improvement in justice increases their perceived health. These results give further support to the notion of a health adverse or health promoting psychosocial work environment. In policy terms, they broaden the focus of workplace health intervention to include justice in managerial treatment.

Despite these merits the conclusions of the paper by Kivimäki et $a l^{9}$ deserve some caution. The obvious limitations of this study are mainly attributable to a lack of externally assessed health measures, the use of a proxy measure of organisational justice, and somewhat inconsistent gender specific results. Moreover, the odds ratios of poor self rated health are comparatively modest, ranging from 1.12 to 1.53 in the fully adjusted models. A further unresolved question concerns the role of socioeconomic status in this analysis. Organisational injustice and poor self rated health were both found to be more prevalent in lower status civil servants. Rather than adjusting for rank an analytical strategy seems promising that explores the mediating or modifying role of organisational justice in this context. Similarly, authors adjusted the effects of relational justice on health for the two work stress models, demand-control and effort-reward imbalance. While this is an instructive approach an analysis of combined effects of the models under study is equally important.

On conceptual and methodological grounds, the analysis of change of exposure over time and its association with change of health must be considered a special strength of this study. It is now evident that occupational stress research needs to move beyond a single (mostly baseline) assessment of occupational exposure to study its dynamics over time. Recent findings from both work stress models mentioned above support this conclusion. ${ }^{4}$ In summary, it is hoped that innovative contributions such as this paper from the Whitehall II research team strengthen the impact of "new" occupational health research for science and policy.

$J$ Epidemiol Community Health 2004;58:888. doi: 10.1136/jech.2004.023218

Correspondence to: Professor J Siegrist, University of Dusseldorf, Institute for Medical Sociology, Dusseldorf, Germany D-40001; siegrist@uni-duesseldorf.de

Funding: none.

Conflicts of interest: none declared.

\section{REFERENCES}

1 Cherermisinoff PM. Encyclopaedia of environmental control technology. Houston: Gulf Publishing, 1994.

2 Davey Smith G, Lynch JW. Socioeconomic differentials. In: Kuh D, Ben-Shlomo Y, eds. A lifecourse approach to chronic disease epidemiology. 2nd ed. Oxford: Oxford University Press, 2004.

3 Stansfeld S, Marmot M. Stress and the heart. London: BMJ Books, 2002.

4 Belkic KL, Landsbergis PA, Schnall PL, et al. Is job strain a major source of cardiovascular disease risk? Scand J Work Environ Health 2004;30:85-128.

5 Siegrist J, Marmot M. Health inequalities and the psychosocial environment-two scientific challenges. Soc Sci Med 2004;58:1463-73.

6 Karasek R, Theorell T. Healthy work. Stress, productivity, and the reconstruction of working life. New York: Basic Books, 1990.

7 Siegrist J. Effort-reward imbalance at work and health. In: Perrewe P, Ganster D, eds. Research in occupational stress and well being, historical and current perspectives on stress and health. New York: JAl Elsevier, 2002:261-91.

8 Kivimäki $M$, Leino-Arjas $A P$, Luukkonen $R$, et al. Work stress and risk of cardiovascular mortality: Prospective cohort study of industrial employees. BMJ 2002;325:857-60.

9 Kivimäki M, Ferrie JE, Head J, et al. Organisational justice and change in justice as predictors of employee health: the Whitehall II study. J Epidemiol Community Health 2004;58:931-7. 
Sexual health

\section{The promiscuous 10\%?}

\section{Mark A Bellis, Karen Hughes, John R Ashton}

\section{A high price is paid by ignoring the needs of the promiscuous $10 \%$}

W th few exceptions every month uncovers more evidence of the declining sexual health of the UK population. ${ }^{12}$ Levels of chlamydia have more than doubled in the past 10 years, ${ }^{1}$ nearly forgotten infections such as syphilis have returned to plague new generations ${ }^{3}$ and overall, sexually transmitted infections (STIs) are higher than at any time since the National Health Service began in 1948. ${ }^{4}$ Furthermore, while some reductions have been made in teenage pregnancy rates, these have been modest and still leave the UK with one of the highest rates in Europe. ${ }^{5}$ By and large our attempts to avoid a sexual health crisis and, more recently, to manage it have failed.

At the core of this crisis is an unwillingness to engage with the "promiscuous" 10\%; a significant group of people who have multiple sexual partners, may have started sex early in life, and may even access paid sex and pornography. For instance, one in ten young people have had sex at 14 or younger. ${ }^{6}$ Such individuals who have sex at an earlier age are less likely to use condoms at sexual initiation, are more likely to become pregnant earlier, ${ }^{6}$ and accumulate more sexual partners per year. ${ }^{7}$ Changing their behaviour is central to improving sexual health but these individuals are rarely the principal consideration when developing interventions. For instance, school based sex education is the main source of information on sex issues for young people. ${ }^{6}$ Evidence suggests that early sex education does not encourage early sexual activity $^{8}$ but is central to young people obtaining appropriate information on sex, sexual health and relationships along with the skills required to manage these. ${ }^{9}$ However, with the exception of some biological details, sex education effectively remains outside of the national curriculum for England. Decisions on when, what, and how much sex education (if any) is delivered are made largely within each school. Thus, at national levels the choice to guarantee the delivery of high quality sex education is evaded, often to avoid offence to a sensitive but vocal minority. Equally at a local level the same individuals steer teachers and governors away from the needs of the promiscuous $10 \%$ and paradoxically towards the wishes of those relatively unaffected by the sexual health crisis. The result can be little or irrelevant sex education, delivered by embarrassed teachers after many children have become sexually active.

The irony of sexual health interventions accommodating those least affected, rather than those most at risk, continues outside of schools. Among UK adults, around one in ten women have had at least two sexual partners concurrently in the past 12 months and for men this rises to nearly one in eight. ${ }^{10}$ Such behaviour is regularly the focus of television, film, and other forms of media content but in general without reference to sexual health. In the United States, (a source of broadcast content for many countries), $64 \%$ of general television programmes contain some form of sexual activity, yet just 15\% deal with sexual health. ${ }^{11}$ Equally in the UK, adverts use strong sexual imagery to sell everything from alcohol to cars. However, the condom is practically never seen unwrapped by a well toned man or a half naked woman. ${ }^{12}$ Despite around half of the sexually active adult population using them, ${ }^{13}$ portrayals of condoms remain limited to the cold or the comedic. Overall, adverts and programmes seem unwilling to deal with sexual health issues. Those that try often suffer a backlash from the vocal minority who seem accepting of widespread sexual innuendo but critical of media addressing sexual health through the same mechanisms. Recently, for example, in the UK a billboard advertisement for Durex used inflated condoms to spell out the words Roger More and was banned after just a few complaints. ${ }^{14}$ However, advertising regulations ${ }^{15}$ should only prevent messages or images that may cause serious or widespread offence. Overall, UK advertising and programme content avoid condoms, negotiation of safe sex, and other aspects of sexual health. In doing so they may reduce complaints from the more sensitive but only at the expense of safer sex featuring as a facet of promiscuous behaviour.

The results of not engaging the promiscuous now include $10 \%$ of sexually active UK adults having had a sexually transmitted infection and around 13\% of the general population having visited a genitourinary medicine (GUM) clinic. ${ }^{16}$ Among those with higher numbers of sexual partners the figures are even worse with over one in five individuals who have had 10 or more sexual partners having been to a GUM clinic. ${ }^{17}$

In fact, sexual health services, in particular GUM services, may be the first place promiscuous individuals receive information they regard as relevant. All too often this comes after they have been infected with a STI or found themselves unintentionally pregnant. However, GUM clinics in the UK remain grossly under-resourced to work with these individuals, to change their sexual practice, and to explore the infection status and sexual practice of their contacts. ${ }^{18}$ As a result the same individuals return for treatment with new infections often after acquiring new unprotected sexual contacts. ${ }^{19}$ Thus, over three quarters of GUM attendees in London have had a previous $\mathrm{STI}^{20}$ and almost a quarter of 12 to 15 year olds presenting at GUM clinics with gonorrhoea return to services with another episode of the disease within 12 months. ${ }^{18}$

It seems that even in specialist settings there is not enough time and resource to meet the needs of the $10 \%$ and denigrating opinion about their behaviour makes them unlikely to complain publicly. Consequently, increasing waiting lists at GUM services mean that in the UK nearly half of STIs are now first diagnosed in primary care. $^{21}$ However, it is at least questionable how well general practitioners are prepared to tackle the needs of the promiscuous $10 \%$, to discuss their sexual practice, and advise on protecting their own and their partners' sexual health. ${ }^{22}$ For instance, nearly $5 \%$ of adult males in the UK have paid for $\operatorname{sex}^{10}$ and both prostitutes and clients are more likely to have high numbers of sexual partners and be at heightened risk of STIs. ${ }^{23}{ }^{24}$ Discussion of such risk taking is unlikely as personal conflicts between generations, sexualities, and even religious beliefs inhibit communication not just in schools and the media but also between health professionals and the more promiscuous. As a result issues such as prostitution are addressed largely as judicial problems instead of as public health concerns.

The promiscuous 10\% could access sexual health information on the internet. The medium is already strongly associated with sex and in just one month almost a quarter of all home internet users in the UK will access pornography, with a quarter of these being students. ${ }^{25}$ Furthermore, those 
using the medium to find sexual partners take more sexual risks ${ }^{26}$ and, in the case of young people, start sex earlier. ${ }^{27}$ Many good sexual health sites are already available. However for the young, protective filters on home computers sensibly bar access to pornography but incidentally often bar access to safer sex sites as well. ${ }^{28}$ Parents can change web browsers to allow access to safe sex sites but this requires a sexual health dialogue between parent and child. All too often this dialogue is absent especially for those who have started sex or even an interest in sex early. ${ }^{6}$

In reality of course there is no specific promiscuous $10 \%$ as many individuals move in and out of polygamy, serial monogamy, long term monogamy, and even abstinence. However, meeting the needs of the most sexually active, whatever the terminology, lies in giving more consideration to their needs when planning educational curriculums, media campaigns, and health interventions. With some areas seeing one in ten young people with a $\mathrm{STI}^{29}$ perhaps a greater level of statutory, pertinent, and timely sex education is now required despite the complaints of a few. More realistic portrayals of sex, condom use, and safer sex practice in the media may again upset a few but may also help counter the sexual innuendo that currently promotes promiscuity but provides no hint of safe sex behaviour. Perhaps even the occasional advert could suggest that condoms, not just aftershave or the right jeans, may help improve your sex life. The price for this will undoubtedly be complaints from a few individuals who find open discussion of sex and sexuality difficult to condone. However, with spiralling numbers of STIs and continuing unwanted pregnancies the price of ignoring the needs of the promiscuous $10 \%$ will be far greater.

$J$ Epidemiol Community Health

2004;58:889-890.

doi: $10.1136 /$ jech.2004.027847

\section{Authors' affiliations}

M A Bellis, K Hughes, Centre for Public Health, Liverpool John Moores University, UK J R Ashton, Government Office North West, UK

Correspondence to: Professor M A Bellis, Director, Centre for Public Health, Liverpool John Moores University, 8 Marybone, Liverpool L3 2AP, UK; m.a.bellis@livjm.ac.uk

Accepted for publication 2 August 2004

Funding: none.

Conflicts of interest: none declared.

\section{REFERENCES}

1 Health Protection Agency. Epidemiological data-sexually transmitted infections. London, Health Protection Agency, 2004 (http:// www.hpa.org.uk/infections/topics_az/ hiv_and_sti/epidemiology/sti_data.htm).

2 Donaldson L. Health check on the state of public health: annual report of the Chief Medical Officer 2003. London: Department of Health, 2004.

3 Bellis MA, Cook P, Clark $P$, et al. Re-emerging syphilis in gay men: a case-control study of behavioural risk factors and HIV status. J Epidemiol Community Health 2002;56:235-6.

4 Terrence Higgins Trust. Shiffing the balance of power in the NHS: modernising HIV and sexual health services. London: Terrence Higgins Trust, 2002

5 UNICEF. A league table of teenage births in rich nations, Innocenti Report Card no 3. Florence: Unicef, 2001

6 Wellings K, Nanchahal K, Macdowall W, et al. Sexual behaviour in Britain: early heterosexual experience. Lancet 2001;358:1843-50.

7 Bellis MA, Hughes K. Sexual behaviourEuropean perspectives on the role of substance use. In: Calafat A, Fernandez C, Juan $M$, et al. Enjoying the nightlife in Europe-the role of moderation. Valencia: IREFREA, 2003.

8 Dickson R, Fuller D, Eastwood A, et al. Preventing and reducing the adverse effects of unintended teenage pregnancies. Effective Health Care Bulletin 1997;3:1-12.

9 House of Commons Health Committee. Sexual health. Third report of session 2002-03. London: The Stationery Office, 2003.

10 Johnson AM, Mercer CH, Erens B, et al. Sexual behaviour in Britain: partnerships, practices, and HIV risk behaviours. Lancet 2001;358:1835-42.

11 Kunkel D, Biely E, Eyal K, et al. Sex on TV 3: a biennial report to the Kaiser Family Foundation. Santa Barbara: University of California, 2003.

12 Bellis MA, Ashton JR. The sexual health of boys and men. BMJ 2000;320:643.

13 National Statistics. Contraception and sexual health 2002. London: Department of Health, 2003.
14 BBC. 'Offensive' condom ad banned, 21 May 2003.http://news.bbc.co.uk/1/hi/health/ 3046247.stm(accessed 20 Nov 2003).

15 Committee of Advertising Practice. The British code of advertising, sales promotion and direct marketing. London: Committee of Advertising Practice, 2003.

16 Fenton KA, Korovessis C, Johnson AM, et al Sexual behaviour in Britain: reported sexually transmitted infections and prevalent genital Chlamydia trachomatis infection. Lancet 2001;358:1851-4

17 Johnson AM, Wadsworth J, Wellings K, et al. Sexual attitudes and lifestyles. Oxford: Blackwell Scientific, 1994.

18 PHLS Communicable Disease Surveillance Centre. Sexual health in Britain: recent changes in high-risk sexual behaviours and the epidemiology of sexually transmitted infections including HIV. London: PHLS Communicable Disease Surveillance Centre, 2002.

19 Hughes G, Brady AR, Catchpole MA, et al. Characteristics of those who repeatedly acquire sexually transmitted infections: a retrospective cohort study of attendees at three urban sexually transmitted disease clinics in England. Sex Transm Dis 2001;28:379-86

20 Filipe EM, Strauss SB, Beck EJ, et al. Sexual behaviour among London GUM clinic attenders: implications for HIV education. Int J STD AIDS 1994:5:346-52.

21 Cassell JA, Brook MG, Mercer CH, et al. Treating sexually transmitted infections in primary care: a missed opportunity? Sex Transm Infect 2003;79:134-6.

22 Stead ML, Brown JM, Fallowfield L, et al. Lack of communication between healthcare professionals and women with ovarian cancer about sexual issues. Br J Cancer 2003; 10:666-71.

23 Moore S. Characteristics, attitudes and risk behaviours of Australian men who visit female sex workers. Venereology 1999;12:7-14.

24 Coughlan E, Mindel A, Estcourt CS. Male clients of female commercial sex workers: HIV, STDs and risk behaviour. Int J STD AIDS 2001;12:665-9.

25 BBC. Britons drawn to online porn, 10 Aug 2001.http://news.bbc.co.uk/1/hi/sci/tech/ 1484003.stm (accessed 1 Aug 2004).

26 Benotsch EG, Kalichman S, Cage M. Men who have met sexual partners via the Internet: prevalence, predictors, and implications for HIV prevention. Arch Sex Behav 2002;31:177-83.

27 McFarlane M, Bull SS, Rietmeijer CA. Young adults on the internet: risk behaviors for sexually transmitted diseases and HIV. J Adolesc Health 2002;31:11-16.

28 Hughes K, Bellis MA, Tocque K. Information and communications technologies in public health: tackling health and digital inequalities in the information age. Liverpool: Centre for Public Health, Liverpool John Moores University, 2002.

29 Department of Health. A pilot study of opportunistic screening for Chlaymdia trachomatis infection in England (1999-2000). London: Department of Health, 2002

A workshop organised by the

\section{Rebuilding health care in Iraq}

\section{Andrew S Furber, Paul Johnstone}

\section{Advocacy and technical support required to support professional colleagues in Iraq}

$\mathrm{T}$ he effects of three wars within 25 years, ${ }^{1}$ a decade of international sanctions, ${ }^{2}$ and a brutal regime have had tragic consequences on Iraq's health system and on the health of the Iraqi people. $^{3}$ While the scale of these problems is becoming clearer, it has been difficult in the current security situation
International Committee of the Faculty of Public Health (FPH) in November 2003 has now addressed this very issue. ${ }^{4}$ This paper describes the health service needs presented at the workshop by representatives from the Department for International Development (DFID), World Health Organisation (WHO), International Non-Governmental Organisations (INGOs) and, most importantly, Iraq's Ministry of Health. We will also consider current responses and how professional public health bodies from around the world might 
contribute to the development of Iraq's health sector.

The priority health service needs of Iraq where professional public health organisations could usefully contribute fall into four broad areas: communicable diseases, primary care development, health management, and public health training. These areas were identified as being of key importance by the participants at the workshop with recent experience in Iraq and concur with the assessment of the Iraqi Ministry of Health ${ }^{56}$ and findings of the donor meeting in Madrid. ${ }^{7}$

The potential for the outbreak of infectious diseases is clear and immediate. The cold chain for the delivery of vaccines has broken down in many parts of the country. ${ }^{8}$ Primary care facilities are often not administering the immunisation programme in an efficient manner-and even where facilities are functional staffing remains variable.' Such disruption will also affect other communicable disease control programmes such as that for tuberculosis. Water supply and sanitation are poor, especially in parts of the country where fighting was the fiercest, resulting in episodes of watery and bloody diarrhoea. The incidence of diarrhoeal disease has been reported to have doubled in some areas of the country. ${ }^{10}$ The causes of these cases are often unknown as laboratory facilities are still not functioning in a way that permits microbiological diagnosis. Laboratories have suffered from systematic looting and therefore lack basic equipment. Clinical reporting from primary care facilities remains inadequate to properly monitor patterns of infectious disease. However, despite all this there have been no major outbreaks of infectious disease reported, according to Tim Healing, a microbiologist working for WHO. This is probably attributable to the basic clinical skills of Iraqi healthcare workers and the prioritisation of communicable disease control by NGOs and WHO. While a public health catastrophe has thus far been averted, the dangerous conditions still exist that would allow for serious outbreaks of communicable disease.

While primary care facilities are improving, it is clear that many remained poorly staffed and inadequately equipped. At the FPH workshop, Linda Doull, Health Advisor from the INGO Merlin, described their programme for the re-establishment of primary care facilities. While this has had some success (showing that it remains possible to see improvement even in difficult security situations), there is still a long way to go. Merlin has been able to distribute emergency health kits, water storage equipment, chlorine tablets, and health promotion leaflets. ${ }^{10}$ Although such process indicators are encouraging, outcomes are more difficult to measure. Good outcomes from such programmes will be reduced by the on-going security problems. Many parts of the country do not have similar primary care support programmes.

Retaining the central role of primary care is part of the challenge of managing Iraq's health system. ${ }^{11} \mathrm{~A}$ health system based on primary health care remains an effective approach in resource constrained settings. ${ }^{12}$ The Ministry of Health in Iraq has yet to set a vision for the future of the country's health system, according to Jürgen Schmidt, Health Advisor with DFID. While broad targets have been set in terms of, for example, electricity and water supply, it seems that no objectives have been set for reconstruction within the health sector. This leads to reluctance from the donors to become involved in long term investment in this sector and is compounded by weak management capacity within Iraq, both at central and governerate levels. ${ }^{*}$

The causes of this lack of management capacity are complex, but it is clear that there is a key training need ${ }^{11}$ and a priority area identified by WHO. ${ }^{13}$ The effects of the wars, the sanctions, and the restrictive regime have meant that most health administrators and healthcare workers who have remained within the country have had little professional development over the past 15 years or so. ${ }^{14}$ Medical libraries, where they still exist, are stocked with out of date journals and text books. Internet access remains poor for most health professionals resulting in limited access to online resources. Postal and courier services are either unreliable or absent making it difficult to mail resources. Providing training within the country currently represents a significant security risk for both trainer and trainee. ${ }^{15}$ While there are important training needs within all specialist areas, it is clear that during a postwar period of development and investment the need for skills in public health and health systems management are particularly urgent. Another pressing need is for a rapid expansion of nursing capacity, which is currently inadequate at all levels. There is an important opportunity for professional nursing organisations to ensure this area is not neglected.

The expectation of the people of Iraq for the rapid development of health services is important and needs to be

*There are 18 governerates within Iraq, each having a director of health services. recognised. However, it is unlikely that these expectations will be met in the short term. It is also possible that these aspirations are distorting the donor response. There is evidence, for example, that funds have been allocated to the reconstruction of metropolitan hospitals ahead of primary care development. ${ }^{2}$ This is probably in part attributable to the need to have some highly visible health projects both for the Iraqi people and the international media. In reality Iraq must aim for the health system of a middle income country in the short term and leave ambitions for an expensive technology based service until a later date. Managing these expectations and demonstrating important health improvements achieved through primary care development will be an important role for public health practitioners.

A major issue that affects existing health services and any efforts to develop them is that of security. While acknowledging the extreme difficulty faced by the occupying forces, it is nevertheless lamentable that health services were not better protected. ${ }^{16}$ The maintenance of essential services is a responsibility of the occupying powers. A political solution is required to bring the long term stability required to fully develop the country's health services. Making this link clear to governments and pressing them for action will be an important advocacy role for health professionals. The current security situation makes travel to Iraq for expatriates extremely hazardous and in most cases inadvisable. Therefore, while not ideal, most training initiatives for Iraqi health professionals will need to be done either remotely or out of country.

Given these pressing needs and the important constraints we have described, what is the best way to support professional colleagues in Iraq? The FPH International Committee's Workshop identified two broad areas for action: advocacy and technical support. Advocacy from professional organisations can be an important influence when there is a widespread public perception that government actions may be driven more by domestic political considerations than the needs of the Iraqi people. Particularly in the period before a democratic government becomes established in Iraq, advocacy can be a way of ensuring that the human rights of the Iraqi population are given the highest priority by those in authority. The Faculty of Public Health and other professional bodies can have an important role in influencing the response to postwar Iraq. In particular it needs to be made clear that there is a humanitarian duty to ensure that the 
health of the Iraqi people remains central. While it remains vital to secure the broader determinants of health, such as security, employment, and water supply, the Iraqi Health Ministry needs to work with the Interim Iraqi government with support from the international community to build a vision for health sector development. The FPH needs to join with similar bodies to lobby governments to ensure this happens.

In terms of practical support there is a need for more professional and technical connections. Poor access to journals, training, and continuing professional development are key issues for many Iraqi professionals, many of whom were trained in the UK. International exchanges and provision of information will be important drivers for improvement. However, caution needs to be exerted. Inappropriate "study tours" to technology based health systems may create more dissatisfaction and increase emigration by professionals from Iraq. The FPH hope to establish a post to help carefully coordinate training exchanges to ensure that they are appropriate. Exposure to academic training and service National Health Service work for short periods will be valuable in updating public health competencies and emphasising the centrality of primary care, as well as establishing longer term supportive partnerships.
Despite the concern that many public health professionals may have over the decision to go to war in Iraq, we are now faced with an important opportunity to help meet major public health needs. Within the UK the FPH will provide one channel for such work, but many more will be required throughout the world.

\section{ACKNOWLEDGEMENTS}

The authors are grateful to all those who participated in the International Committee's Workshop and to those who reviewed the paper.

\section{$J$ Epidemiol Community Health}

2004;58:890-892.

doi: 10.1136/jech.2003.019216

\section{Authors' affiliations}

A S Furber, School of Health and Related Research, University of Sheffield, Sheffield, UK P Johnstone, Government Office for Yorkshire and The Humber, Leeds, UK

Correspondence to: Dr A Furber, School of Health and Related Research, University of Sheffield, Regent Court, 30 Regent Street, Sheffield S1 4DA, UK; A.Furber@sheffield.ac. uk

Funding: none.

Conflicts of interest: none declared.

\section{REFERENCES}

1 Farooq S, Guitard I, McCoy D, et al. Continuing collateral damage: the health and environmental costs of war on Iraq 2003. Medact, London,
2003. http://www.medact.org (accessed 19 Dec 2003).

2 Editorial. Health effects of sanctions on Iraq. Lancet 1995;346:1439.

3 Fleck F. Iraq health minister seeks more funds for future health system. BMJ 2003;327:889.

4 Anwar S, Furber A, Johnstone P.

Making a difference: the health of Iraq. Report of the Faculty of Public Health International Committee Winter Workshop 2003. London: Faculty of Public Health, 2004, http:// www.fph.org.uk/Events/Past_events/2003/ international_comm_workshop_report_12.03.pdf (accessed 27 Jan 2004).

5 Fleck F. Iraq health minister plans future Iraqi health system. Bull WHO 2003;81:848-9.

6 Fleck F. Swapping llford for Baghdad. BMJ 2004;328:1280.

7 International Donors' Conference for the reconstruction of Iraq. http:// www.comisionadoiraq.org/donors/ index_ing.htm (accessed 22 Jun 2004).

8 Ni'ma SA, Imad AAK, Faiza AAM, et al. Vaccination services in post war Iraq, May 2003. MMWR. 2003;52: 734-5, http://www.cdc.gov/ $\mathrm{mmwr} / \mathrm{preview} / \mathrm{mmwrhtml} / \mathrm{mm} 5231 \mathrm{a} 3 \mathrm{htm}$ (accessed 29 Jan 2004).

9 Frankish H. Health of the Iraqi people hangs in the balance. Lancet 2003:361:623-5.

10 Merlin. Iraq: preventing illness associated with diarrhoeal disease, http://www.merlin.org.uk/ template6asp?PagelD = 162 (accessed 17 Jun 2004).

11 Garfield R. Challenges to health service development in Iraq. Lancet 2003;362:1324.

12 Dugbatey K. National health policies: subSaharan African case studies (1980-1990). Soc Sci Med 1999:49:223-39.

13 Kapp C. Donors pledge US $\$ 33$ billion for Iraq, but problems remain. Lancet 2003;362:1467.

14 Amin NMM, Khoshnaw MQ. Medical education and training in Iraq. Lancet 2003;362:1326.

15 Aziz C. Struggling to rebuild Iraq's health-care system. Lancet 2003;362:1288-9.

16 De Ceukelaire W, Jabbour S, Stephens C. Securing Iraq's health. [Letter]. Lancet 2003;362:1938.

\section{THE JECH GALLERY}

\section{"5-a-day" may be harder to achieve in more deprived areas}

ncreasing the public's intake of fresh fruit and vegetables is a major public health objective. Pronounced differences between social groups in fruit and vegetable intake have been observed and lack of access may contribute to patterns of consumption. ${ }^{1}$ In our study of socially contrasting localities in Glasgow, we have noticed differences in retail outlets that may contribute to lower consumption of fruit and vegetables in the more deprived locality. ${ }^{2}$

Anne Ellaway, Sally Macintyre MRC Social and Public Health Sciences Unit, University of Glasgow, 4 Lilybank Gardens, Glasgow G12 8RZ, UK

Correspondence to: Dr A Ellaway; anne@msoc.mrc.gla.ac.uk,

\section{REFERENCES}

1 Morland K, Wing S, Roux AD. The contextual effect of the local food environment on residents' diets: The atherosclerosis risk in communities study. Am J Public Health 2002;92:1761-7.

2 Ellaway A, Macintyre S. Does where you live predict health related behaviours? A case study in Glasgow. Health Bull 1996;54:443-6.

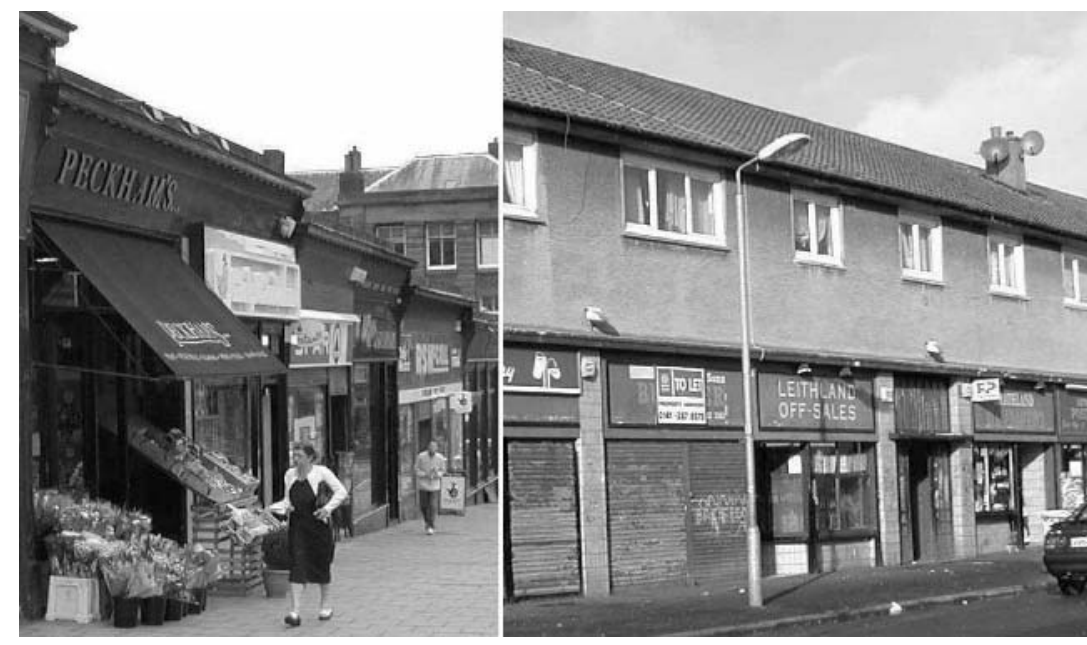

